\title{
Addressing the challenges to successful recruitment and retention in Alzheimer's disease clinical trials
}

Joshua D Grill*1 and Jason Karlawish²

\begin{abstract}
Among the key challenges in Alzheimer's disease drug development is the timely completion of clinical trials. Unfortunately, clinical trials often suffer from slow or insufficient enrollment. Successful clinical trial recruitment describes a balance between expeditiously achieving full enrollment and ensuring an appropriate study sample. Investigators face a number of challenges to the successful negotiation of this balance. The failure to address these challenges means that drug development may take more time and money and that trial results may not adequately represent drug efficacy or may not be applicable beyond the study. We review the challenges to recruitment and retention in Alzheimer's disease clinical trials and present a framework to address them.
\end{abstract}

\section{Introduction}

Alzheimer's disease (AD) affects millions worldwide and is associated with tremendous human and financial costs. Because the prevalence of $\mathrm{AD}$ is increasing and no medications alter disease progression, there is great need for new therapies. Developing these therapies relies upon the clinical trial, but AD trials face challenges. This review focuses on the challenges to effective recruitment and retention of participants. The failure to address these challenges has a number of costs. It can halt a trial, render a scientific question unanswered, and waste precious resources-most critically the time, effort, and health of participants.

\footnotetext{
*Correspondence: jgrill@mednet.ucla.edu

'Mary S Easton Center for Alzheimer's Disease Research, Department of Neurology, University of California, Los Angeles, 10911 Weyburn Avenue, Suite 200,

Los Angeles, CA 90095, USA

Full list of author information is available at the end of the article
}

After a review of the literature and experiences in $A D$ clinical trial conduct, this paper summarizes the challenges related to $\mathrm{AD}$ trial recruitment and retention for phase II and phase III randomized, placebo-controlled trials of treatments that target the underlying biology or cognitive symptoms associated with AD. We discuss how trial design and conduct can affect recruitment. We examine why recruited participants may not adequately represent the greater disease-suffering population. We overview the barriers to recruitment related to the study participants: both AD patients and their study partners. We discuss the challenges to retention of participants in $\mathrm{AD}$ trials. To address these issues, we propose changes to study recruitment practices and attempt to guide investigators to consider potential pitfalls in the way they conduct recruitment and retention.

\section{Trial design and conduct can affect recruitment}

Success in meeting enrollment goals is not simply about advertising and outreach. Studies that are too long, require too many visits, or target enrollment of a population too difficult to recruit are in danger of slow or inadequate enrollment. In Table 1, we provide a literature summary of the rates of recruitment to a sample of multicenter AD trials. For these trials, we have calculated a summary recruitment rate statistic (RR) that is an approximation of the number of subjects recruited per study site per month for a given trial. Every trial faces unique challenges to recruitment, and every trial has its own recruitment goals. As such, comparisons among trials must be made carefully. Moreover, the data within Table 1 speak only to the rapidity with which a trial reached full enrollment. Timely fulfillment of the proposed study enrollment is only one part of a truly 'successful' recruitment. Perhaps more important is the recruitment of a population of participants who are likely to complete the trial, are indeed afflicted with AD, and are representative of others with $\mathrm{AD}$ who will not be enrolled. Within a given trial, choices related to study design have a major impact on whether a trial achieves successful enrollment. 
Table 1. Recruitment rates from a sample of Phase II and Phase III Alzheimer's disease clinical trials

\begin{tabular}{|c|c|c|c|c|c|c|c|}
\hline & Treatment under study & $\begin{array}{c}\text { Study } \\
\text { enrollment }\end{array}$ & Sites & $\begin{array}{l}\text { Enrollment, } \\
\text { months }\end{array}$ & $\mathrm{RR}^{\mathrm{a}}$ & Screened & $\begin{array}{c}\text { Screen } \\
\text { ratio }^{b}\end{array}$ \\
\hline \multirow[t]{7}{*}{ Mild cognitive impairment } & Rofecoxib [54] & 1,457 & 46 & 24 & 1.32 & 2,849 & 1.95 \\
\hline & Rivastigmine [55] & 1,018 & 65 & 12 & 1.30 & 1,526 & 1.50 \\
\hline & Two studies of galantamine [56] & 2,057 & 177 & 12 & 0.97 & 2,759 & 1.35 \\
\hline & Donepezil [57] & 270 & 22 & 16 & 0.77 & 588 & 2.18 \\
\hline & Vitamin E and donepezil [38] & 790 & 69 & 23 & 0.49 & 2,264 & 2.87 \\
\hline & TRIMCI study of trifusal [7] & $257 c$ & 29 & 24 & 0.36 & NA & NA \\
\hline & Donepezil [58] & 821 & 91 & 28 & 0.32 & 2,037 & 2.48 \\
\hline \multirow[t]{12}{*}{ Mild-to-moderate AD } & Dimebon [59] & 183 & 11 & 6 & 2.77 & 230 & 1.26 \\
\hline & Idebenone [60] & 536 & 39 & 12 & 1.14 & 729 & 1.36 \\
\hline & DHA (Joseph Quinn, personal communication) & 402 & 52 & 8 & 0.96 & 555 & 1.39 \\
\hline & AN1792 [61] & 372 & 28 & 16 & 0.83 & NA & NA \\
\hline & Rofecoxib [37] & 351 & 40 & 11 & 0.80 & 474 & 1.35 \\
\hline & Tarenflurbil [9] & 1,684 & 133 & 21 & 0.60 & 2,408 & 1.43 \\
\hline & Gamma secretase inhibitor [62] & 51 & 6 & 51 & 0.57 & 71 & 1.39 \\
\hline & Rivastigmine patch $[63,64]$ & 1,195 & 100 & 22 & 0.54 & 1,464 & 1.22 \\
\hline & Bapineuzumab [10] & 234 & 30 & 16 & 0.49 & 317 & 1.35 \\
\hline & Rosiglitazone [65] & 518 & 67 & 17 & 0.45 & 687 & 1.33 \\
\hline & High-dose B vitamin [66] & 409 & 40 & 27 & 0.26 & 601 & 1.47 \\
\hline & Estrogen replacement [6] & 120 & 39 & 32 & 0.10 & 153 & 1.27 \\
\hline \multirow[t]{5}{*}{ Moderate-to-severe/Severe AD } & Memantine [13] & 404 & 37 & 6 & 1.82 & 589 & 1.46 \\
\hline & Memantine [12] & 252 & 32 & 9 & 0.875 & 345 & 1.37 \\
\hline & Memantine [67] & 350 & 35 & 17 & 0.59 & 547 & 1.56 \\
\hline & Donepezil [5] & 249 & 50 & 18 & 0.28 & 334 & 1.34 \\
\hline & Donepezil [68] & 343 & 91 & 44 & 0.09 & 543 & 1.58 \\
\hline
\end{tabular}

aRecruitment rate statistic, number of participants per site per month. Reported numbers are gross estimates from data reported in publications rather than exact calculations of recruitment rates averaged across study sites. ${ }^{b}$ Number of patients screened for every enrolled subject. ${ }^{C}$ Failed to meet enrollment goals. AD, Alzheimer's disease; DHA, docosahexaenoic acid; NA, not available.

\section{Visit frequency and study length}

Decisions related to the total length of a study and the frequency of study visits are guided by study goals and often by concerns over safety. It is logical to expect that the longer the study and the greater the number of study visits, the greater the burden on participants and the more difficult recruitment will be. Trials of agents with high risk profiles or for which the risk profile is largely unknown often require more visits to ensure patient safety. For example, early-phase studies (phase I or IIa) are often shorter (on the order of weeks to months) and require more frequent study visits than later-phase studies. Phase II AD trials of gamma secretase inhibitors have commonly used every-other-week study visits [1], making participation more daunting, especially for individuals who travel great distances to participate. In contrast, late-phase studies (phase IIb or III) that aim to evaluate efficacy are commonly at least 18 months long. These trials generally use study visits every 3 months.
Less commonly, the intervention itself necessitates a more frequent rate of study visits. Ongoing trials of some immunotherapies for $\mathrm{AD}$ use medication infusions once or twice per month.

\section{Selection of the targeted Alzheimer's disease population}

The target population is defined by the inclusion and exclusion criteria that participants must meet to enroll. Inclusion criteria should be designed to enroll only patients who truly suffer from $A D$ and to maximize the likelihood of demonstrating a difference between drug and placebo when one exists [2]. Inclusion criteria generally identify a patient population of a specific disease severity. This is most often defined by a range of scores on the Mini-Mental State Examination (MMSE) [3]. Challenges in enrollment are not limited to trials of specific disease severities. As can be seen in the sample of published $\mathrm{AD}$ trials described in Table 1, examples of studies with fast rates of enrollment (for example, RR $>1$ ) 
exist for all disease severities. Similarly, slow enrollment can occur in trials in all stages of disease severity. Trials that fail to complete enrollment are also likely to go unpublished, given the probability that they will fail to meet the primary outcome [4]. To be clear, recruitment of participants with more severe disease faces unique challenges in comparison with studies of milder disease. Careful design and unique recruitment strategies, however, can be undertaken to overcome such challenges [5].

Besides disease severity, other specifications related to the population to be recruited can impact the rate of enrollment. For example, the Alzheimer's Disease Cooperative Study (ADCS) trial of estrogen replacement enrolled only women who had mild-to-moderate $\mathrm{AD}$ and who had undergone hysterectomy. Despite a somewhat wider range of MMSE inclusion criteria (12 to 28) than is typical, this trial enrolled only an average 10 subjects per month across 39 sites, and it took more than 3 years to complete enrollment [6].

\section{Medication-related decisions}

Criteria that exclude a large number of concomitant medications, though often necessary to ensure participant safety, can hinder recruitment. Many AD patients take supplements such as ginkgo biloba, and some trials exclude these patients. Alternatively, in trials examining available medications or supplements for therapeutic benefit in $\mathrm{AD}$, the greater availability of these agents can pose a challenge to enrollment. The TRIMCI study of the anti-inflammatory agent trifusal in amnestic mild cognitive impairment (MCI) failed to meet its recruitment goals because of the high incidence of non-steroidal anti-inflammatory drug use among potential participants, which was exclusionary [7]. A recent trial of latrepirdine (formerly dimebon) excluded patients taking medications currently approved by the US Food and Drug Administration (FDA) for the treatment of AD. This study was conducted in part in the US, where there is a high prevalence of use of these prescription medications among those diagnosed with AD. The data related to recruitment for this trial are not yet available.

To increase the appeal to participants seeking new treatments, some studies incorporate alternate allocation, whereby randomly assigned participants have a greater chance of being assigned to an active treatment group than the placebo group. Although this may increase the appeal of participation to some patients, alternate allocation also requires increased sample size to maintain statistical power and it remains unclear whether this strategy abbreviates the total study recruitment period [8].

\section{Design changes made after study initiation}

Changes to study conduct after trial initiation but before the close of enrollment can impact recruitment. The original entry criteria for a phase III trial of tarenflurbil included mild-to-moderate AD patients with an MMSE score of between 15 and 26. Three months after enrollment began, the MMSE criteria for entry were changed to 20 to 26 as a result of findings from a phase II study [9]. Overall trial recruitment occurred from February 2005 until April 2008. Such changes mid-enrollment can counteract previous recruitment strategies. Similarly, stopping a study medication dose prior to closing enrollment is likely to impact recruitment. Dosing changes, especially those brought about by safety concerns, must be communicated to new participants as part of informed consent and may deter enrollment of new subjects. The high dose of the anti-amyloid antibody bapineuzumab was halted for safety reasons prior to closure of enrollment in a recent phase III study. Alternatively, the publication of positive data related to a study drug might improve enrollment. The same phase III study of bapineuzumab was still enrolling when data were published from phase II efficacy [10] and biomarker [11] trials. Data on the recruitment rates for the bapineuzumab phase III study are not yet available. Trials of drugs for which previous positive trials have been conducted are likely to enroll quickly. The initial trial of memantine in moderate-to-severe AD (MMSE 3 to 14) enrolled 252 subjects at 32 US sites over the course of 9 months [12] and demonstrated a significant difference from placebo on the primary efficacy outcomes. Consequently, a trial of memantine in moderate-to-severe $\mathrm{AD}$ (MMSE 5 to 14) patients taking donepezil efficiently enrolled 404 patients at 37 trial sites over the course of 6 months [13].

\section{Barriers to recruitment impact Alzheimer's disease patients and their study partners and shape trial populations}

Successful trial enrollment faces many barriers, and most $\mathrm{AD}$ trials struggle to enroll. The ADCS trial of docosahexaenoic acid (DHA) enrolled 400 mild-to-moderate $\mathrm{AD}$ patients in 8 months, 10 months ahead of schedule, making it unique among AD trials. The agent tested in this trial funded by the National Institutes of Health was considered safe, allowing less restrictive inclusion and exclusion criteria. The trial also employed a 60/40 alternate allocation ratio toward active treatment. The factor that may have had the greatest impact on trial recruitment, however, was that it was conducted during a period in which few other trials in mild-to-moderate $\mathrm{AD}$ were recruiting and competition for subjects was minimal (Joseph Quinn, Oregon Health and Science University, Portland, OR, USA, personal communication).

As discussed, successful recruitment means more than just timely fulfillment of enrollment goals. Trial participants should be representative of the greater $\mathrm{AD}$ 
population. The mean age of participants in the DHA trial was 75.6 years. Fifty-three percent of participants were female. These demographic factors are fairly representative of the greater AD-suffering population. Participants in the DHA trial averaged 14.1 years of education. The over-representation of highly educated participants is common among AD trial populations [14] and stands in stark contrast to epidemiologic studies, which consistently demonstrate that less than 12 years of education is a significant risk factor for $\mathrm{AD}[15,16]$. In the DHA trial, $90 \%$ of participants were Caucasian. Faison and colleagues [17] examined the race of AD trial participants, comparing 737 ADCS trial participants with 10,800 industry-sponsored trial participants. The authors found that only $10 \%$ of ADCS and 3\% of industry-sponsored trial participants were non-Caucasian [17]. Given that African-Americans and Hispanics are at greater risk for $\mathrm{AD}$ than Caucasians $[18,19]$ and that the proportion of AD sufferers who are of minority race or ethnicity will increase faster than that of Caucasians in coming decades [20], the low rates of minority enrollment in trials must be improved.

Among study partners in the DHA trial, 65\% were female and $68 \%$ were spouses of the participant. The patient's primary caregiver most often fills the role of study partner and there are roughly 11 million persons in the US caring for a dementia patient. The majority of $\mathrm{AD}$ caregivers are women. Only a fraction of caregivers in the US, however, are spouses. The majority of caregivers are non-spousal family members, including primarily those who care for a parent or a parent-in-law [20]. The high representation of spousal caregivers in AD trials is striking and important. Trials offer patients and families an opportunity to feel active and involved in their medical care and in medical science's attempts to help them, others like them, and future generations. Many enroll in AD trials, however, in pursuit of therapeutic benefit. Spousal caregivers may have greater motivation than do adult children caregivers to pursue new therapeutic options. Alternatively, there may be increased barriers to participation for adult children caregivers, who are more likely to be working full-time, more likely to have young families, and thus less likely to have the scheduling flexibility to participate in clinical trials in the 9-to-5 clinic schedules in which they are generally conducted.

The overall differences between the enrolled population and the general $\mathrm{AD}$ population are troubling. They suggest that the barriers to recruitment and retention significantly shape the population under study and call into question the notion that the results of $\mathrm{AD}$ trials will be broadly applicable beyond a given study. We will next examine the various barriers to recruitment of $\mathrm{AD}$ trial participants, including the patient and the caregiver study partner.

\section{Barriers related to the Alzheimer's disease patient-caregiver dyad}

The decision to enroll in an $\mathrm{AD}$ trial is made by two people: the patient and their study partner. In this way, recruitment to $\mathrm{AD}$ trials is twice as difficult as recruitment to clinical trials that enroll only the patient. Those who choose to participate in a clinical trial commit significant time and energy. This commitment is justified out of hope for personal and societal benefit and trust in the investigator and study site [21]. The commitment is made with an understanding of given risks and requirements. Both the patient participant and the study partner participant must give informed consent and both must commit to full participation. Of course, patientcaregiver dyads cannot choose to participate unless they are aware of studies. At diagnosis, referral to trials is uncommon [22]. Thus, participation by those seeing physicians who do not personally conduct trials often requires active pursuit of information about study opportunities. Yet even when the patient and the study partner are aware of trials, they are still likely to encounter several barriers to trial participation. The barriers and facilitators of AD trial enrollment related to patients and caregivers are summarized in Table 2.

\section{Barriers related to the Alzheimer's disease patient}

Many AD patients who wish to participate in a clinical trial may not be eligible to do so. AD patients are, by definition, older. Older patients are likely to suffer from comorbidities that exclude participation. For example, current trials of immunotherapies exclude participants for a previous infarct (observed via magnetic resonance imaging [MRI]), even if it results in no neurologic sign or symptom. Given the high incidence of overlap between AD and vascular pathology [23], a substantial number of patients who might otherwise qualify for a trial may fail to be included, because of this criterion.

Older patients, especially in the US, also take a high number of prescription medications, which may similarly exclude participation. Even if these patients do not take an exclusionary medication at screening, trial protocols instruct investigators to enroll only patients whose medication profiles are stable and not likely to change through the course of the study. Protocols generally include patients taking $\mathrm{AD}$ medications, although these medications are subject to the same requirements. Thus, when enrolling mild patients who take only an acetylcholinesterase inhibitor (AChEI), the investigator is forced to consider whether to enroll the patient or start memantine (approved only in moderate-to-severe disease) to ensure stability through the course of the trial. Choosing the latter forces a delay in trial initiation and increases the likelihood that the patient will not be enrolled due to study closure or another reason. 
Table 2. Facilitators and barriers to participation in Alzheimer's disease clinical trials

\begin{tabular}{|c|c|c|c|}
\hline Factor & Impact & $\begin{array}{l}\text { Participant } \\
\text { affected }\end{array}$ & Description \\
\hline Low trial awareness & - & B & Those not aware of trials cannot participate. \\
\hline Comorbidities & - & P & $\begin{array}{l}\text { Patients with cardiovascular disease, cerebrovascular lesions, or other medical problems } \\
\text { are likely to be excluded. }\end{array}$ \\
\hline Medications & - & P & $\begin{array}{l}\text { Patients taking a high number of prescription medications are likely to be excluded from } \\
\text { participation. Specific trials may have other criteria (for example, excluding medications } \\
\text { approved for AD) that prevent some patients from participating. }\end{array}$ \\
\hline Risks of side effects & - & B & $\begin{array}{l}\text { Risks associated with investigational therapies are barriers to patients and their study } \\
\text { partners, who often identify risks to the patient as 'personal' risk. }\end{array}$ \\
\hline Barriers associated with procedures & - & P & $\begin{array}{l}\text { Patients may be unwilling to undergo procedures such as lumbar puncture, unable to } \\
\text { undergo MRIs, or suffer associated frustration with cognitive testing. }\end{array}$ \\
\hline Risk of placebo & - & B & $\begin{array}{l}\text { Some dyads enroll primarily out of hope for access to new treatments. For these persons, } \\
\text { the possibility of receiving placebo is a barrier to participation. }\end{array}$ \\
\hline Travel and other logistics & - & B & The requirement of attending study visits at the medical center can deter participation. \\
\hline Language barriers & - & B & $\begin{array}{l}\text { Only patients and study partners who both are capable of fluent communication in the } \\
\text { language acceptable for participation are generally eligible to enroll. }\end{array}$ \\
\hline Informed consent & - & P & $\begin{array}{l}\text { Patients who are not aware of their impairment may lack the capacity to give informed } \\
\text { consent. }\end{array}$ \\
\hline Informed consent & + & B & $\begin{array}{l}\text { Most trials allow a legally authorized representative to provide informed consent on } \\
\text { behalf of the patient. }\end{array}$ \\
\hline Access to new treatments & + & B & Many participants enroll in trials in the hope of direct medical benefit for the patient. \\
\hline Altruism & + & B & $\begin{array}{l}\text { The desire to assist medical research is a commonly cited reason for participating in AD } \\
\text { trials. }\end{array}$ \\
\hline
\end{tabular}

Impact: Facilitator (+), barrier (-). Participant impacted: patient (P) or both (B) patient and caregiver. AD, Alzheimer's disease; MRI, magnetic resonance imaging.

Previous participation in an AD trial may exclude enrollment. Late-stage trials generally exclude participants of earlier-phase studies of the same drug. Similarly, most trials of active or passive immunization now exclude patients who have previously participated in a trial of any AD immunotherapy. In fact, for some ongoing trials, choosing to enroll means lifelong participation in one and only one trial. For example, the ADCS trial of nerve growth factor gene transfer aims to follow participants to autopsy and, given that subjects receive a therapy that is anticipated to deliver its therapeutic effect for as long as the neurons receiving it survive, being accepted into other trials is unlikely for recipients of the active therapy.

Some patients may be unwilling or unable to participate because of the procedures involved in a study. Individuals with pacemakers cannot undergo study-required MRIs and thus are excluded from trials that require imaging to ensure safety or use volumetric measures as mandatory outcomes. Many patients experience anxiety related to study procedures such as lumbar punctures. One phase II investigation of a gamma secretase inhibitor in prodromal $\mathrm{AD}$ is enrolling participants in the randomly assigned treatment trial only if they meet specific criteria related to cerebrospinal fluid protein analysis. Individuals unable or unwilling to undergo lumbar puncture are ineligible. Neuropsychological testing remains the hallmark of AD trials, co-primary outcome measures for all registration trials include one cognitive measure, and essentially all trials include a broad array of psychometric tests. For many trials, cognitive testing batteries are limited to the English language. Often, individuals not able to complete cognitive testing in the available languages at a study site are excluded. Such testing may require 3 to 5 hours to complete and can result in frustration and distress for the participant [24]. In subjects aware of their impairment, the reminder of their cognitive struggles can be overwhelming and may result in an unwillingness to participate.

Not all AD patients are aware of their impairment and those who lack insight may also lack the capacity to give informed consent. Some recent trials of aggressive therapies exclude individuals not able to demonstrate the capacity to provide consent. In these trials, the inability to comprehend trial-related procedures and risks is a barrier to participation. The majority of $\mathrm{AD}$ trials, however, facilitate participation by permitting a legally authorized representative to give the informed consent on behalf of a patient who lacks the capacity to do so for him- or herself. Most AD patients wish to be involved in the decision of whether to participate [25], and dyads that enroll in trials are likely to reach a joint decision. Although it is not clear how often it occurs, disagreement between patients and caregivers about participation can be a barrier to enrollment [21]. 


\section{Barriers related to the study partner}

Patients who do not have a suitable study partner cannot be enrolled in AD trials. The study partner must be an individual familiar with the patient's medical and personal situation and the primary caregiver most often fills this critical role. At screening, the study partner provides an accurate medical history. Following enrollment, they provide transportation to study visits and serve as informants in a variety of study procedures and outcome measures. Between study visits, they monitor study and medication adherence.

The role of the caregiver in the decision to participate in an $\mathrm{AD}$ trial is as important as that of the patient. Often, caregivers choose to participate in AD clinical trials out of hope for medical benefit for the patient [21, 26-28]. Other motivations include desperation resulting from a lack of other treatment options [21,26] and a desire to help medical science pursue a cure $[21,26,27$, 29,30]. Trials offer the opportunity to interact with AD experts and access to new technologies that might not be covered by insurance.

If a study partner faces insurmountable barriers to participation, then it is unlikely that the patient will participate. Caregivers who decline participation cite a variety of factors that lead to their decision. Some caregivers cite the need to travel to the study site [21], and offering car services to facilitate transportation or performing at least a portion of study visits in the home increases the likelihood that caregivers will support a decision to participate [31]. Individuals who report travel as a barrier, however, are not necessarily those who reside furthest from study sites. This suggests that, at least for some caregivers who decline participation, emotional and attitudinal factors about the logistics of travel play a large role.

Caregivers also face emotional burdens [32-34]. They often cite the fear of side effects for the patient as a barrier to participation $[21,28]$. Many caregivers do not distinguish risks or benefits for the patient from risks or benefits for themselves [21]. The patient is most often a spouse or parent, and the caregiver does not wish to increase the patient's medical burden. Furthermore, increased medical burden for the patient is increased burden on the primary caregiver.

Finally, some caregivers cite the risk that the patient will not benefit from participation as a barrier to enrollment [27]. Some caregivers who decline enrollment cite doubts about the potential efficacy of the agent under investigation as reason for refusing participation [28]. These caregivers may defer participation in one trial to participate in another, more promising study. The same individuals are likely to cite the 'risk' of placebo as a deterrent to participation.

\section{What factors impact trial retention?}

Regulatory and ethical guidelines mandate that participants can withdraw their consent to participate in a clinical study at any time. Therefore, good retention begins prior to enrollment, by recruiting study participants who are likely to complete a trial. Once trial conduct is initiated, making participation as convenient as possible for subjects and study partners optimizes retention.

Steps should be taken to inform participants of their value and the value of the research in which they are participating. Newsletters informing participants of trial progress can facilitate the feeling of being part of a larger agenda. For centers or investigators conducting multiple trials, annual luncheons honoring research participants can be effective retention tools, although these events must be conducted with sensitivity to participant confidentiality and privacy.

A variety of factors can impact trial retention. Examples of trials that had poor retention exist, but often these trials faced extenuating challenges. A trial in mild-tomoderate AD of atorvastatin enrolled 98 participants, of whom 15 withdrew consent prior to random assignment 'primarily to participate in other trials' [35]. Similarly, the ADCS trial of dihydroepiandrosterone initially recruited 58 participants, but only 33 completed the 12 -month trial [36]. Fifty-three percent of subjects randomly assigned to placebo dropped out of the study prior to completion, and the authors hypothesized that the high rate of dropout may have been the result of the widespread availability of FDA-approved AChEI therapies during study conduct [36].

We examined the retention rates in a sample of $\mathrm{AD}$ trials (Table 3). Although some trials may include a low dose without expectation of therapeutic benefit, we chose to combine all active treatment doses in a single category. In the very few occasions in which two active treatments were tested against placebo [37,38], we combined all active treatments in a single group. In cases in which participants completed a study off-medication, they have been included as completers whenever possible. Importantly, this summary is limited largely to trial reports in primary manuscripts rather than analysis of raw data and should be interpreted accordingly.

Table 3 shows that the majority of subjects who enroll in $\mathrm{AD}$ trials are retained through trial completion and that, across disease severities, these rates do not substantively vary. MCI trials had an average retention rate of $71.6 \%$, mild-to-moderate $\mathrm{AD}$ trials $77.7 \%$, and moderate-to-severe and severe AD trials $75.4 \%$. One might expect that, independent of disease severity, retention is easier in shorter trials. Even among some of the longest trials conducted, however, retention rates are high. Alternatively, some of the lower rates are for 6-month studies. 
Table 3. Retention rates from a sample of Phase II and Phase III Alzheimer's disease clinical trials

\begin{tabular}{|c|c|c|c|c|c|}
\hline & Treatment under study & $\begin{array}{c}\text { Study } \\
\text { enrollment }\end{array}$ & $\begin{array}{c}\text { Active } \\
\text { completers }\end{array}$ & $\begin{array}{c}\text { Placebo } \\
\text { completers }\end{array}$ & $\begin{array}{c}\begin{array}{c}\text { Trial } \\
\text { length, } \\
\text { months }\end{array} \\
\end{array}$ \\
\hline \multirow[t]{7}{*}{ Mild cognitive impairment } & Rofecoxib [54] & 1,457 & $687 / 725=0.95$ & $702 / 732=0.96$ & 48 \\
\hline & TRIMCI study of trifusal [7] & 257 & $104 / 129=0.81$ & $119 / 128=0.93$ & 18 \\
\hline & Donepezil [57] & 270 & $90 / 133=0.68$ & $114 / 137=0.83$ & 6 \\
\hline & Vitamin E and donepezil [38] & 790 & $346 / 510=0.68$ & $193 / 259=0.74$ & 36 \\
\hline & Rivastigmine [55] & 1,018 & $312 / 508=0.61$ & $346 / 510=0.68$ & 48 \\
\hline & Donepezil [58] & 821 & $226 / 409=0.55$ & $273 / 412=0.66$ & 12 \\
\hline & Two studies of galantamine [56] & 2,057 & $476 / 1,029=0.46$ & $543 / 1,028=0.53$ & 24 \\
\hline \multirow[t]{15}{*}{ Mild-to-moderate AD } & Dimebon [59] & 183 & $78 / 89=0.88$ & $77 / 94=0.82$ & 4 \\
\hline & Gamma secretase inhibitor [62] & 51 & $32 / 36=0.89$ & $12 / 15=0.80$ & 4 \\
\hline & Rosiglitazone [65] & 518 & $106 / 122=0.87$ & $336 / 389=0.86$ & 6 \\
\hline & High-dose B vitamin [66] & 409 & $204 / 240=0.85$ & $140 / 169=0.83$ & 18 \\
\hline & Rivastigmine patch $[63,64]$ & 1,195 & $704 / 893=0.79$ & $266 / 302=0.88$ & 6 \\
\hline & Estrogen replacement [6] & 120 & $65 / 81=0.80$ & $32 / 39=0.82$ & 15 \\
\hline & Galantamine [69] & 978 & $539 / 692=0.78$ & $240 / 286=0.84$ & 5 \\
\hline & Rofecoxib [37] & 351 & $179 / 240=0.74$ & $88 / 111=0.79$ & 12 \\
\hline & DHA (Joseph Quinn, personal communication) & 402 & $178 / 241=0.74$ & $129 / 161=0.80$ & 18 \\
\hline & Bapineuzumab [10] & 234 & $92 / 122=0.75$ & $87 / 107=0.81$ & 18 \\
\hline & AN1792 [61] & 372 & $223 / 299=0.74$ & $53 / 73=0.73$ & 12 \\
\hline & Idebenone [60] & 536 & $281 / 407=0.69$ & $96 / 129=0.74$ & 12 \\
\hline & Atorvastatin [39] & 640 & $207 / 314=0.66$ & $245 / 326=0.75$ & 18 \\
\hline & Galantamine [70] & 636 & $266 / 423=0.63$ & $172 / 213=0.81$ & 6 \\
\hline & Tarenflurbil [9] & 1,684 & $506 / 862=0.59$ & $540 / 822=0.66$ & 18 \\
\hline \multirow[t]{7}{*}{ Moderate-to-severe/Severe AD } & Selegeline/Alpha tocopherol [71] CDR 2 & 341 & $240 / 257=0.93$ & $78 / 84=0.93$ & 24 \\
\hline & Donepezil [72] MMSE 5 to 17 & 291 & $121 / 144=0.84$ & $126 / 146=0.86$ & 6 \\
\hline & Donepezil [5] MMSE 1 to 10 & 249 & $95 / 128=0.74$ & $99 / 120=0.82$ & 6 \\
\hline & Memantine [67] MMSE 5 to 14 & 350 & $134 / 178=0.75$ & $126 / 172=0.73$ & 6 \\
\hline & Memantine [12] MMSE 3 to 14 & 252 & $97 / 126=0.77$ & $84 / 126=0.67$ & 7 \\
\hline & Donepezil [68] MMSE 1 to 12 & 343 & $117 / 176=0.66$ & $127 / 167=0.76$ & 6 \\
\hline & Memantine [13] MMSE 5 to 14 & 404 & $172 / 203=0.85$ & $150 / 201=0.75$ & 6 \\
\hline
\end{tabular}

AD, Alzheimer's disease; CDR, Clinical Dementia Rating; DHA, docosahexaenoic acid; MMSE, Mini-Mental State Examination.

Few of the trials we sampled had a significant difference between the treatment and placebo groups in the percentage of participants who completed the trial $[13,39]$. This supports the idea that altruism is a motivating factor for enrolling and continuing participation. If a patient or caregiver was interested in participation solely for the sake of gaining access to a new therapy, they might be likely to drop out of a trial if they concluded that they were randomly assigned to the placebo group (whether they were correct or not) or if they perceived that the patient is declining despite receiving study medication.

Recent analyses of the ADCS MCI trial of donepezil and vitamin E by Edland and colleagues [40] suggest that a variety of factors within a trial may indicate patients who will drop out prior to study completion. The authors found that the characteristics of participants who were likely to drop out were non-Caucasian race, less than high school education, and being unmarried (that is, having an adult child or child-in-law as a study partner). Furthermore, the analysis suggested that participants recruited to commercial trial sites (as opposed to academic sites) were at increased risk to drop out of a trial. Dropout rates at commercial sites were nearly double those of sites that were $\mathrm{AD}$ research centers funded by the National Institute on Aging [40]. In line with their analyses, in the trials that we reviewed, those with the largest study size (and as such were most likely to enlist non-academic sites) had the lowest retention 
rates. Trials with a sample size of greater than 1,000 had a mean retention rate of $70.6 \%$. Alternatively, the smallest trials examined (fewer than 300) had higher rates of retention (81.4\%). Similarly, trials conducted by the ADCS had an $81.2 \%$ mean retention rate. The remaining trials averaged a $73.2 \%$ retention.

\section{Outlook for the future}

What is the available pool of patients for Alzheimer's disease trials?

Many promising therapies are in clinical development for $\mathrm{AD}$ and more will enter clinical trials in coming years. To plan the recruitment of adequate subject populations for these trials, it will be necessary to better understand the pool of eligible patients qualified to participate. More than 400,000 Americans are diagnosed with AD annually [41]. Hence, investigators might assume that they have an ample (and growing) supply of participants for trials. Among all dementia patients, however, roughly half are moderately severe or more advanced in their disease $[42,43]$ and therefore fail to meet the mild-to-moderate category for which most trials currently recruit. The majority of all AD patients are older than 75 years [43], increasing the likelihood of exclusion for reasons such as comorbidities or prohibited medications. In fact, analyses of general clinical AD populations suggest that only $10 \%$ to $13 \%$ are eligible for clinical trials $[44,45]$. In sum, the pool of eligible trial participants for AD trials is limited.

In 2009, at least seven phase III trials (of five drugs) recruiting in the US required a combined total of 8,510 participants (solanezumab [LY2062430] $\mathrm{n}=1,000$ [ClinicalTrials.gov ID NCT00905372] and $\mathrm{n}=1,000$ [NCT00904683]; semagecestat [LY450139] $\mathrm{n}=1,100$ [NCT00762411] and $\mathrm{n}=1,700$ [NCT01035138]; bapineuzumab $\mathrm{n}=1,300$ [NCT00574132] and $\mathrm{n}=1,000$ [NCT00575055]; dimebon $\mathrm{n}=1,050$ [NCT00829374]; and intravenous immunoglobulin $\mathrm{n}=360$ [NCT00818662] [1]). There were more, though smaller, phase II studies. Screening ratios are generally better than 2:1 (2 patients screened to enroll 1) (Table 1), but the fact remains that a significant number of patients recruited will not be enrolled. Thus, if one considers the newly diagnosed patients each year, the barriers to enrollment, and the number of participants needed as multiple trials are conducted simultaneously, it is clear that the recruitment needs for AD clinical trials will remain a challenge that results in competition for eligible subjects. Strategies to overcome the current barriers to recruitment must be developed.

\section{How can trial recruitment be optimized?}

The most straightforward approach to improving the rate of enrollment is to increase the number of trial sites. AD trials have become increasingly 'global', enrolling from multiple countries and continents within single studies. This change brings potential methodological [46] as well as ethical challenges when less industrialized nations are involved for which access to the drug (once it is approved) is not likely [47] (Declaration of Helsinki). Moreover, trial recruitment is difficult in all countries, not just the US [48]. It has been shown that, with increasing trial site number, the likelihood of placebo decline is reduced [49]. Furthermore, expanding the number of trial sites results in the inclusion of sites that are not focused on AD as a therapeutic area.

AD trials are optimally performed at trial sites experienced in their specific conduct by staffs well versed in the issues $\mathrm{AD}$ patients and their families face. Trials can be designed to facilitate participation for the subject and their study partner. Performing visits in the home and otherwise limiting travel hassles will increase the willingness to participate among caregivers.

Awareness of trials must be increased. Efforts to increase awareness should target both patients and caregivers. The fact that most caregivers are adult children but most study partners are spouses indicates that there remains a large number of uninformed or unwilling potential participant dyads. Social media may provide an avenue to specifically target adult children caregivers. The Wisconsin Registry for Alzheimer's Prevention has successfully enrolled more than 1,400 middle-aged adult children of AD patients in a natural history study [50], and the use of television advertising has been an effective means of recruitment. Similarly, web-based patient registries such as www.patientslikeme.com [51] have been used effectively in other therapeutic areas. Internet use among those over the age of 65 is increasing, and 'wired seniors' are likely to seek health-care information specifically when online [52]. AD models of registries have been proposed and could target MCI and mild-stage AD potential participants and caregivers and also potential participants in prevention trials, such as baby boomers [53].

The advantage of disseminating the message of the value of clinical trials is to diversify the reasons why people enroll. The more reasons a person has for being in a trial, the more likely he or she is to enroll and, over time, stay in a trial. As participants experience adverse events and the efforts of study visits, those participants whose reasons for enrollment include trust in the investigator and a desire to help others are more likely to stay in a trial than are patients whose sole motivation is benefit to their health. This is especially true in AD clinical trials in which, to date, therapeutic benefit has been elusive.

Effective methods to limit competition among trials, facilitate enrollment, and match eligible candidates with appropriate trials would improve recruitment and 
retention and result in a more rapid drug development. Agencies to fill such needs could have a major impact on clinical research. Such agencies, however, should be supported by federal and state governments, not forprofit entities, and would thus be free of private corporate interests.

\section{Conclusions}

In summary, clinical trials in $\mathrm{AD}$ face a variety of challenges to recruitment and retention. Many trials struggle to complete enrollment in a timely fashion despite substantial effort. Trial enrollment may not represent the greater disease-suffering population, and this may result in trial findings that are not readily applicable beyond the study. AD trial retention is largely effective, although some variation does exist and is likely related to the population recruited and the caliber of study conduct. Responses to these challenges and improvement to recruitment and retention can and should be made. All eligible subjects must be made aware of participation opportunities, and trials must be designed in a manner that makes participation feasible for patient-caregiver dyads.

\section{Abbreviations}

AChEl, acetylcholinesterase inhibitor; AD, Alzheimer's disease; ADCS, Alzheimer's Disease Cooperative Study; DHA, docosahexaenoic acid; FDA, US Food and Drug Administration; MCl, mild cognitive impairment; MMSE, MiniMental State Examination; MRI, magnetic resonance imaging; RR, recruitment rate statistic.

\section{Competing interests}

JDG is the site investigator for clinical trials sponsored by Elan (Dublin, Ireland), Janssen-Cilag GmbH (Neuss, Germany), Bristol-Myers Squibb Company (Princeton, NJ, USA), Medivation (San Francisco, CA, USA), Pfizer Inc (New York, NY, USA), and the National Institute on Aging-sponsored Alzheimer's Disease Cooperative Study. He is the principal investigator of a clinical trial sponsored by the John Douglas French Alzheimer's Foundation (medical food generously supplied by Accera Pharma, Broomfield, CO, USA). He has served as a paid consultant to Avanir Pharmaceuticals (Aliso Viejo, CA, USA). JK is the site investigator for a clinical trial sponsored by Pfizer Inc.

\section{Author details}

'Mary S Easton Center for Alzheimer's Disease Research, Department of Neurology, University of California, Los Angeles, 10911 Weyburn Avenue, Suite 200, Los Angeles, CA 90095, USA. PPenn Memory Center, Penn Center for Bioethics, Departments of Medicine and Medical Ethics, University of Pennsylvania, Chestnut Street, Philadelphia, PA 19104, USA.

\section{Acknowledgments}

The authors wish to acknowledge Paul Aisen and Joseph Quinn for making the data related to the ADCS trial of DHA available and the participants in all of the clinical trials discussed in this review. JDG is supported by NIA AG016570 and by the Sidell-Kagan Foundation. JK is supported by NIA P30AG10124 and the Marian S. Ware Alzheimer Program.

Published: 21 December 2010

\section{References}

1. ClinicalTrials.gov homepage [www.clinicaltrials.gov].

2. Leber PD, Davis CS: Threats to the validity of clinical trials employing enrichment strategies for sample selection. Control Clin Trials 1998, 19:178-187.

3. Folstein MF, Folstein SE, McHugh PR: 'Mini-mental state'. A practical method for grading the cognitive state of patients for the clinician. J Psychiatr Res 1975, 12:189-198.

4. Haidich $A B$, loannidis JP: Effect of early patient enrollment on the time to completion and publication of randomized controlled trials. Am 」 Epidemiol 2001, 154:873-880.

5. Winblad B, Kilander L, Eriksson S, Minthon L, Batsman S, Wetterholm AL, Jansson-Blixt C, Haglund A: Donepezil in patients with severe Alzheimer's disease: double-blind, parallel-group, placebo-controlled study. Lancet 2006, 367:1057-1065.

6. Mulnard RA, Cotman CW, Kawas C, van Dyck CH, Sano M, Doody R, Koss E, Pfeiffer E, Jin S, Gamst A, Grundman M, Thomas R, Thal L: Estrogen replacement therapy for treatment of mild to moderate Alzheimer disease: a randomized controlled trial. Alzheimer's Disease Cooperative Study. JAMA 2000, 283:1007-1015.

7. Gómez-Isla T, Blesa R, Boada M, Clarimón J, Del Ser T, Domenech G, Ferro JM, Gómez-Ansón B, Manubens JM, Martínez-Lage JM, Muñoz D, Peña-Casanova J, Torres F; TRIMCI Study Group: A randomized, double-blind, placebo controlled-trial of triflusal in mild cognitive impairment: the TRIMCI study. Alzheimer Dis Assoc Disord 2008, 22:21-29.

8. Vozdolska R, Sano M, Aisen P, Edland SD: The net effect of alternative allocation ratios on recruitment time and trial cost. Clin Trials 2009, 6:126-132.

9. Green RC, Schneider LS, Amato DA, Beelen AP, Wilcock G, Swabb EA, Zavitz KH: Effect of Tarenflurbil on Cognitive Decline and Activities of Daily Living in Patients With Mild Alzheimer Disease: A Randomized Controlled Trial. JAMA 2009, 302:2557-2564.

10. Salloway S, Sperling R, Gilman S, Fox NC, Blennow K, Raskind M, Sabbagh M, Honig LS, Doody R, van Dyck CH, Mulnard R, Barakos J, Gregg KM, Liu E, Lieberburg I, Schenk D, Black R, Grundman M; Bapineuzumab 201 Clinical Trial Investigators: A phase 2 multiple ascending dose trial of bapineuzumab in mild to moderate Alzheimer disease. Neurology 2009, 73:2061-2070.

11. Rinne JO, Brooks DJ, Rossor MN, Fox NC, Bullock R, Klunk WE, Mathis CA, Blennow K, Barakos J, Okello AA, Rodriguez Martinez de Liano S, Liu E, Koller M, Gregg KM, Schenk D, Black R, Grundman M: 11C-PiB PET assessment of change in fibrillar amyloid-beta load in patients with Alzheimer's disease treated with bapineuzumab: a phase 2 , double-blind, placebo-controlled, ascending-dose study. Lancet Neurol 2010, 9:363-372.

12. Reisberg B, Doody R, Stoffler A, Schmitt F, Ferris S, Mobius HJ: Memantine in moderate-to-severe Alzheimer's disease. N Engl J Med 2003, 348:1333-1341.

13. Tariot PN, Farlow MR, Grossberg GT, Graham SM, McDonald S, Gergel I: Memantine treatment in patients with moderate to severe Alzheimer disease already receiving donepezil: a randomized controlled trial. JAMA 2004, 291:317-324.

14. Albert SM, Sano M, Marder K, Jacobs DM, Brandt J, Albert M, Stern Y: Participation in clinical trials and long-term outcomes in Alzheimer's disease. Neurology 1997, 49:38-43.

15. Kukull WA, Higdon R, Bowen JD, McCormick WC, Teri L, Schellenberg GD, van Belle G, Jolley L, Larson EB: Dementia and Alzheimer disease incidence: a prospective cohort study. Arch Neurol 2002, 59:1737-1746.

16. Stern Y, Gurland B, Tatemichi TK, Tang MX, Wilder D, Mayeux R: Influence of education and occupation on the incidence of Alzheimer's disease. JAMA 1994, 271:1004-1010

17. Faison WE, Schultz SK, Aerssens J, Alvidrez J, Anand R, Farrer LA, Jarvik L, Manly J, McRae T, Murphy GM Jr., Olin JT, Regier D, Sano M, Mintzer JE: Potential ethnic modifiers in the assessment and treatment of Alzheimer's disease: challenges for the future. Int Psychogeriatr 2007, 19:539-558.

18. Evans DA, Bennett DA, Wilson RS, Bienias JL, Morris MC, Scherr PA, Hebert LE, Aggarwal N, Beckett LA, Joglekar R, Berry-Kravis E, Schneider J: Incidence of Alzheimer disease in a biracial urban community: relation to apolipoprotein E allele status. Arch Neurol 2003, 60:185-189.

19. Tang MX, Cross P, Andrews H, Jacobs DM, Small S, Bell K, Merchant C, Lantigua R, Costa R, Stern Y, Mayeux R: Incidence of AD in AfricanAmericans, Caribbean Hispanics, and Caucasians in northern Manhattan. Neurology 2001, 56:49-56.

20. Alzheimer's Association: 2010 Alzheimer's disease facts and figures. Alzheimers Dement 2010, 6:158-194.

21. Karlawish JH, Casarett D, Klocinski J, Sankar P: How do AD patients and their caregivers decide whether to enroll in a clinical trial? Neurology 2001, 56:789-792.

22. Carr SA, Davis R, Spencer D, Smart M, Hudson J, Freeman S, Cooper GE, 
Schmitt FA, Markesbery WR, Danner D, Jicha GA: Comparison of recruitment efforts targeted at primary care physicians versus the community at large for participation in Alzheimer disease clinical trials. Alzheimer Dis Assoc Disord 2010, 24:165-170.

23. Schneider JA, Arvanitakis Z, Bang W, Bennett DA: Mixed brain pathologies account for most dementia cases in community-dwelling older persons. Neurology 2007, 69:2197-2204.

24. Lai JM, Hawkins KA, Gross CP, Karlawish JH: Self-reported distress after cognitive testing in patients with Alzheimer's disease. J Gerontol A Biol Sci Med Sci 2008, 63:855-859.

25. Hirschman KB, Joyce CM, James BD, Xie SX, Karlawish JH: Do Alzheimer's disease patients want to participate in a treatment decision, and would their caregivers let them? Gerontologist 2005, 45:381-388.

26. Sugarman J, Cain C, Wallace R, Welsh-Bohmer KA: How proxies make decisions about research for patients with Alzheimer's disease. J Am Geriatr Soc 2001, 49:1110-1119.

27. Connell CM, Shaw BA, Holmes SB, Foster NL: Caregivers' attitudes toward their family members' participation in Alzheimer disease research: implications for recruitment and retention. Alzheimer Dis Assoc Disord 2001, 15:137-145.

28. Elad P, Treves TA, Drory M, Verchovsky R, Klimovitsky S, Ben-Laish S, Yaron S, Ginzburg K, Korczyn AD: Demented patients' participation in a clinical trial: factors affecting the caregivers' decision. Int I Geriatr Psychiatry 2000 15:325-330.

29. Mastwyk M, Macfarlane S, LoGiudice D, Sullivan KA: Why participate in an Alzheimer's disease clinical trial? Is it of benefit to carers and patients? Int Psychogeriatr 2003, 15:149-156.

30. Mastwyk M, Ritchie CW, LoGiudice D, Sullivan KA, Macfarlane S: Carer impressions of participation in Alzheimer's disease clinical trials: what are their hopes? And is it worth it? Int Psychogeriatr 2002, 14:39-45.

31. Karlawish J, Cary MS, Rubright J, Tenhave T: How redesigning AD clinical trials might increase study partners' willingness to participate. Neurology 2008, 71:1883-1888

32. Brodaty $\mathrm{H}$, Green A: Defining the role of the caregiver in Alzheimer's disease treatment. Drugs Aging 2002, 19:891-898.

33. Gonzalez-Salvador MT, Arango C, Lyketsos CG, Barba AC: The stress and psychological morbidity of the Alzheimer patient caregiver. Int I Geriatr Psychiatry 1999, 14:701-710.

34. Grafstrom M, Winblad B: Family burden in the care of the demented and nondemented elderly--a longitudinal study. Alzheimer Dis Assoc Disord 1995, 9:78-86.

35. Sparks DL Sabbagh MN, Connor DJ, Lopez J, Launer $\sqcup$, Browne P Wasser D, Johnson-Traver S, Lochhead J, Ziolwolski C: Atorvastatin for the treatment of mild to moderate Alzheimer disease: preliminary results. Arch Neurol 2005, 62:753-757.

36. Wolkowitz OM, Kramer JH, Reus VI, Costa MM, Yaffe K, Walton P, Raskind M, Peskind E, Newhouse P, Sack D, De Souza E, Sadowsky C, Roberts E; DHEA-Alzheimer's Disease Collaborative Research: DHEA treatment of Alzheimer's disease: a randomized, double-blind, placebo-controlled study. Neurology 2003, 60:1071-1076.

37. Aisen PS, Schafer KA, Grundman M, Pfeiffer E, Sano M, Davis KL, Farlow MR, Jin $S$, Thomas RG, Thal $\mathrm{L}$ : Effects of rofecoxib or naproxen vs placebo on Alzheimer disease progression: a randomized controlled trial. JAMA 2003, 289:2819-2826.

38. Petersen RC, Thomas RG, Grundman M, Bennett D, Doody R, Ferris S, Galasko D, Jin S, Kaye J, Levey A, Pfeiffer E, Sano M, van Dyck CH, Thal LJ; Alzheimer's Disease Cooperative Study Group: Vitamin E and donepezil for the treatment of mild cognitive impairment. N Engl J Med 2005, 352:2379-2388.

39. Feldman HH, Doody RS, Kivipelto M, Sparks DL, Waters DD, Jones RW, Schwam E, Schindler R, Hey-Hadavi J, DeMicco DA, Breazna A: Randomized controlled trial of atorvastatin in mild to moderate Alzheimer disease: LEADe. Neurology 2010, 74:956-964.

40. Edland SD, Emond JA, Aisen PS, Petersen RC: NIA-funded Alzheimer centers are more efficient than commercial clinical recruitment sites for conducting secondary prevention trials of dementia. Alzheimer Dis Assoc Disord 2010, 24:159-164

41. Hebert LE, Beckett LA, Scherr PA, Evans DA: Annual incidence of Alzheimer disease in the United States projected to the years 2000 through 2050. Alzheimer Dis Assoc Disord 2001, 15:169-173.

42. Helmer C, Peres K, Letenneur L, Guttierez-Robledo LM, Ramaroson H, Barberger-Gateau P, Fabrigoule C, Orgogozo JM, Dartigues JF: Dementia in subjects aged 75 years or over within the PAQUID cohort: prevalence and burden by severity. Dement Geriatr Cogn Disord 2006, 22:87-94.

43. Hebert LE, Scherr PA, Bienias JL, Bennett DA, Evans DA: Alzheimer disease in the US population: prevalence estimates using the 2000 census. Arch Neurol 2003, 60:1119-1122.

44. Schneider LS, Olin JT, Lyness SA, Chui HC: Eligibility of Alzheimer's disease clinic patients for clinical trials. J Am Geriatr Soc 1997, 45:923-928.

45. Treves TA, Verchovsky R, Klimovitsky S, Korczyn AD: Recruitment rate to drug trials for dementia of the Alzheimer type. Alzheimer Dis Assoc Disord 2000, 14:209-211.

46. Schindler RJ: Study design considerations: conducting global clinical trials in early Alzheimer's disease. J Nutr Health Aging 2010, 14:312-314.

47. Glickman SW, McHutchison JG, Peterson ED, Cairns CB, Harrington RA, Califf RM, Schulman KA: Ethical and scientific implications of the globalization of clinical research. N Eng/ J Med 2009, 360:816-823.

48. Homma A: Current status of clinical trials for Alzheimer-type dementia in Japan: strategies to facilitate the development of antidementia drugs. Alzheimer Dis Assoc Disord 2000, 14 Suppl 1:S123-126.

49. Gold M: Study design factors and patient demographics and their effect on the decline of placebo-treated subjects in randomized clinical trials in Alzheimer's disease. J Clin Psychiatry 2007, 68:430-438.

50. Wisconsin Registry for Alzheimer's Prevention (WRAP) [http://www.wai. wisc.edu/research/wrap.html].

51. PatientsLikeMe homepage [www.patientslikeme.com].

52. Fox S: Older Americans and the internet. In 2004 Project Report. Washington, DC: The Pew Internet \& American Life Project; 2004.

53. Khachaturian ZS, Barnes D, Einstein R, Johnson S, Lee V, Roses A, Sager MA, Shankle WR, Snyder PJ, Petersen RC, Schellenberg G, Trojanowski J, Aisen P, Albert MS, Breitner JC, Buckholtz N, Carrillo M, Ferris S, Greenberg BD, Grundman M, Khachaturian AS, Kuller LH, Lopez OL, Maruff P, Mohs RC, Morrison-Bogorad M, Phelps C, Reiman E, Sabbagh M, Sano M, Schneider LS, Siemers E, Tariot P, Touchon J, Vellas B, Bain L: Developing a national strategy to prevent dementia: Leon Thal Symposium 2009. Alzheimers Dement 2010, 6:89-97.

54. Thal $\amalg$, Ferris $S H$, Kirby L, Block GA, Lines CR, Yuen E, Assaid C, Nessly ML, Norman BA, Baranak CC, Reines SA: A randomized, double-blind, study of rofecoxib in patients with mild cognitive impairment. Neuropsychopharmacology 2005, 30:1204-1215.

55. Feldman HH, Ferris S, Winblad B, Sfikas N, Mancione L, He Y, Tekin S, Burns A, Cummings J, del Ser T, Inzitari D, Orgogozo JM, Sauer H, Scheltens P, Scarpini E, Herrmann N, Farlow M, Potkin S, Charles HC, Fox NC, Lane R: Effect of rivastigmine on delay to diagnosis of Alzheimer's disease from mild cognitive impairment: the InDDEx study. Lancet Neurol 2007, 6:501-512.

56. Winblad B, Gauthier S, Scinto L, Feldman H, Wilcock GK, Truyen L, Mayorga AJ, Wang D, Brashear HR, Nye JS: Safety and efficacy of galantamine in subjects with mild cognitive impairment. Neurology 2008, 70:2024-2035.

57. Salloway S, Ferris S, Kluger A, Goldman R, Griesing T, Kumar D, Richardson S: Efficacy of donepezil in mild cognitive impairment: a randomized placebo-controlled trial. Neurology 2004, 63:651-657.

58. Doody RS, Ferris SH, Salloway S, Sun Y, Goldman R, Watkins WE, Xu Y, Murthy AK: Donepezil treatment of patients with MCl: a 48-week randomized placebo-controlled trial. Neurology 2009, 72:1555-1561.

59. Doody RS, Gavrilova SI, Sano M, Thomas RG, Aisen PS, Bachurin SO, Seely L, Hung D: Effect of dimebon on cognition, activities of daily living, behaviour, and global function in patients with mild-to-moderate Alzheimer's disease: a randomised, double-blind, placebo-controlled study. Lancet 2008, 372:207-215.

60. Thal $\mathrm{L}$, Grundman M, Berg J, Ernstrom K, Margolin R, Pfeiffer E, Weiner MF, Zamrini E, Thomas RG: Idebenone treatment fails to slow cognitive decline in Alzheimer's disease. Neurology 2003, 61:1498-1502.

61. Gilman S, Koller M, Black RS, Jenkins L, Griffith SG, Fox NC, Eisner L, Kirby L, Rovira MB, Forette F, Orgogozo JM: Clinical effects of Abeta immunization (AN1792) in patients with AD in an interrupted trial. Neurology 2005, 64:1553-1562.

62. Fleisher AS, Raman R, Siemers ER, Becerra L, Clark CM, Dean RA, Farlow MR, Galvin JE, Peskind ER, Quinn JF, Sherzai A, Sowell BB, Aisen PS, Thal LJ: Phase 2 safety trial targeting amyloid beta production with a gamma-secretase inhibitor in Alzheimer disease. Arch Neurol 2008, 65:1031-1038

63. Winblad B, Grossberg G, Frolich L, Farlow M, Zechner S, Nagel J, Lane R: IDEAL: a 6-month, double-blind, placebo-controlled study of the first skin patch for Alzheimer disease. Neurology 2007, 69:514-22. 
64. Winblad B, Cummings J, Andreasen N, Grossberg G, Onofrj M, Sadowsky C, Zechner S, Nagel J, Lane R: A six-month double-blind, randomized, placebo-controlled study of a transdermal patch in Alzheimer's diseaserivastigmine patch versus capsule. Int J Geriatr Psychiatry 2007, 22:456-467.

65. Risner ME, Saunders AM, Altman JF, Ormandy GC, Craft S, Foley IM, ZvartauHind ME, Hosford DA, Roses AD: Efficacy of rosiglitazone in a genetically defined population with mild-to-moderate Alzheimer's disease. Pharmacogenomics J 2006, 6:246-254.

66. Aisen PS, Schneider LS, Sano M, Diaz-Arrastia R, van Dyck CH, Weiner MF, Bottiglieri T, Jin S, Stokes KT, Thomas RG, Thal LJ: High-dose B vitamin supplementation and cognitive decline in Alzheimer disease: a randomized controlled trial. JAMA 2008, 300:1774-1783.

67. van Dyck CH, Tariot PN, Meyers B, Malca Resnick E: A 24-week randomized, controlled trial of memantine in patients with moderate-to-severe Alzheimer disease. Alzheimer Dis Assoc Disord 2007, 21:136-143.

68. Black SE, Doody R, Li H, McRae T, Jambor KM, Xu Y, Sun Y, Perdomo CA, Richardson S: Donepezil preserves cognition and global function in patients with severe Alzheimer disease. Neurology 2007, 69:459-469.

69. Tariot PN, Solomon PR, Morris JC, Kershaw P, Lilienfeld S, Ding C: A 5-month, randomized, placebo-controlled trial of galantamine in $\mathrm{AD}$. The Galantamine USA-10 Study Group. Neurology 2000, 54:2269-2276.
70. Raskind MA, Peskind ER, Wessel T, Yuan W: Galantamine in AD: A 6-month randomized, placebo-controlled trial with a 6-month extension. The Galantamine USA-1 Study Group. Neurology 2000, 54:2261-2268.

71. Sano M, Ernesto C, Thomas RG, Klauber MR, Schafer K, Grundman M, Woodbury P, Growdon J, Cotman CW, Pfeiffer E, Schneider LS, Thal LJ: A controlled trial of selegiline, alpha-tocopherol, or both as treatment for Alzheimer's disease. The Alzheimer's Disease Cooperative Study. N Engl J Med 1997, 336:1216-1222

72. Feldman H, Gauthier S, Hecker J, Vellas B, Subbiah P, Whalen E: A 24-week, randomized, double-blind study of donepezil in moderate to severe Alzheimer's disease. Neurology 2001, 57:613-620.

doi:10.1186/alzrt58

Cite this article as: Grill JD, Karlawish J: Addressing the challenges to successful recruitment and retention in Alzheimer's disease clinical trials. Alzheimer's Research \& Therapy 2010, 2:34. 